\title{
Using registries to identify type 2 diabetes patients
}

\author{
This article was published in the following Dove Press journal: \\ Clinical Epidemiology \\ 18 December 2014 \\ Number of times this article has been viewed
}

\section{Reimar W Thomsen Henrik Toft Sørensen}

Department of Clinical Epidemiology, Aarhus University Hospital, Denmark

Correspondence: Reimar W Thomsen Department of Clincial Epidemiology, Aarhus University Hospital, Olof Palmes Alle 43-45, 8200 Aarhus N, Denmark Email rwt@clin.au.dk
Validation studies of health care registries are considered boring by some. An epidemiologist recently conducted a validation study based on the Danish National Registry of Patients and received the following unflattering comment from a reviewer: "A good example of a paper of limited scope that probably would only be published electronically where space is unlimited". We do not subscribe to this point of view.

Population-based registries based on drug prescriptions and/or physicians' diagnoses or claims in routine care have become a cornerstone in monitoring the rising incidence and prevalence of diabetes in many countries. ${ }^{1-3}$ Alone or in combination with other registries or clinical databases based on primary data collection, these diabetes registries have proven useful for examining the clinical course, complications, and outcome of diabetes. ${ }^{4}$ They are also increasingly used for large real-world studies of comparative drug effectiveness ${ }^{5}$ and adverse drug events. ${ }^{6}$

To be useful for clinical research, these registries must contain reasonably complete data of adequate quality. Two major concerns for diabetes researchers are: 1) can we be sure that an individual recorded with possible diabetes in a registry really has diabetes? and 2) how many diabetes patients in the population would we miss entirely by relying only on, for example, a prescription database or a hospital contact database? It is possible that each type of database captures almost all diabetes patients in any case - perhaps with some delay. Virtually all type 1 diabetes patients and most type 2 diabetes patients will eventually have a hospital stay, and most will eventually receive glucose-lowering prescriptions, given current knowledge about the course of the disease. ${ }^{7}$

A paper in this issue of Clinical Epidemiology provides a thorough validation of the Danish National Diabetes Register (NDR). The NDR combines diabetes data from three existing nationwide population-based Danish health registries: the National Registry of Patients (containing diagnoses given during all hospital contact in Denmark), the National Prescription Registry (containing data on all prescriptions filled at any pharmacy in Denmark), and the Danish National Health Service Register (containing information on frequency of glucose measurements and on podiatrist services).

The study confirms a previous report ${ }^{8}$ that up to $20 \%$ of individuals registered as having diabetes in the NDR may have been included erroneously by using frequently performed blood glucose tests alone (ie, without a diagnostic value) as an indicator of diabetes. When laboratory values of glycated hemoglobin $\left(\mathrm{HbA}_{1 \mathrm{c}}\right)$ measurements become available at the Danish national level in the future, the authors recommend 
using an $\mathrm{HbA}_{1 \mathrm{c}}$ value above $6.5 \%$ as a diagnostic criterion for diabetes. This has already been implemented in other regional Danish studies, ${ }^{9}$ replacing glucose test frequencies.

The authors also focus on classical left truncation bias, as diabetes patients recorded for the first time in the early years of any registry are less likely to be truly "incident cases". The reason is lack of historical data proving that a diagnosis is being made for the first time. Having a longer data history would allow correction of the diagnosis date to an earlier time and thus increase documented diabetes duration. Because disease duration is a major predictor of development of glycemia and its complications, it is an important confounder in studies of drug effectiveness and other prognostic predictors. ${ }^{5}$ Database researchers should allow for a run-in period, excluding the first study years to increase the likelihood of incident cases. As explained by the authors, this is particularly true in studies based on diabetes hospitalizations alone, when even 5 or more years may not suffice. If prescription data are used to identify diabetes, left truncation is less of a problem and shorter run-in periods may be adequate, as glucose-lowering therapy is rarely started and stopped entirely.

In studies that attempt to define type 1 diabetes based on age at diabetes onset (eg, $<40$ years), left truncation may be particularly problematic. An example is patients aged $60+$ years who were receiving insulin as monotherapy when Danish nationwide prescription data became available in 1996. These same patients were 40+ years old in 1977 when Danish hospitalization data became available. As they may or may not have had hospital contact for diabetes at an age much younger than 40 years (before 1977), they cannot be reliably classified as type 1 or type 2 diabetics based on an age criterion.

In analytic epidemiological studies, some misclassification of diabetes is a minor problem as long as the degree of misclassification is similar in the groups being compared. However, in longitudinal incidence and prevalence studies, accuracy in measurement overall and over time is essential. ${ }^{10}$ Current scientific and political concern around the "global diabetes epidemic" is based on such studies.

The validation study presented in this issue of Clinical Epidemiology suggests in a "worst-case scenario" (or is it best case?) that current estimates of the number of persons with known diabetes in Denmark $(n=320,000$ in 2012, 5.7\% of Denmark's population) may be up to $20 \%$ inflated. The reported incidence and prevalence of any disease depends on disease definition and diagnostic efforts. The large increase that the authors observed over time for first primary ascertainment of diabetes based on antidiabetic drug use, rather than hospital diagnoses, is not surprising to the clinical reader. Evolving guidelines have encouraged earlier and more intensive glucose-lowering pharmacotherapy, ${ }^{11}$ and this therapy is commonly started by general practitioners outside hospitals in Denmark. ${ }^{12}$ As has been suggested in earlier studies, ${ }^{13}$ a large component of the currently increasing diabetes prevalence globally may be due to increased diagnostic activity, detecting milder diabetes cases earlier. The validation study in this issue thus provides interesting data beyond plain validation of diagnoses, and proves that validation studies can be both fascinating and important.

\section{Disclosure}

The authors have no conflicts of interest to disclose.

\section{References}

1. Guariguata L, Whiting DR, Hambleton I, Beagley J, Linnenkamp U, Shaw JE. Global estimates of diabetes prevalence for 2013 and projections for 2035. Diabetes Res Clin Pract. 2014;103(2):137-149.

2. Public Health Agency of Canada [homepage on the Internet]. Ottawa: Diabetes in Canada: Facts and figures from a public health perspective; 2011. Available from: http://www.phac-aspc.gc.ca/cd-mc/diabetesdiabete/index-eng.php. Accessed October 2, 2014.

3. NHS Scotland, Diabetes in Scotland [homepage on the Internet]. Scotland: Scottish Diabetes Survey 2013. Available from: http://diabetesinscotland. org.uk/Publications.aspx. Accessed October 2, 2014.

4. Bell S, Fletcher EH, Brady I, et al. End-stage renal disease and survival in people with diabetes: a national database linkage study. $Q J M$. Epub August 19, 2014.

5. Ekström N, Schiöler L, Svensson AM, et al. Effectiveness and safety of metformin in 51675 patients with type 2 diabetes and different levels of renal function: a cohort study from the Swedish National Diabetes Register. BMJ Open. 2012;2(4)

6. Giorda CB, Picariello R, Nada E, et al. Incretin therapies and risk of hospital admission for acute pancreatitis in an unselected population of European patients with type 2 diabetes: a case-control study. Lancet Diabetes Endocrinol. 2014;2(2):111-115.

7. Centre of Registers (Nationella Diabetesregistret) [homepage on the Internet]. Sweden: Swedish National Diabetes Register: Annual report 2013. 2014. Available from: https://www.ndr.nu. Accessed October 2, 2014.

8. Nielsen AA, Christensen H, Lund ED, Christensen C, Brandslund I, Green A. Diabetes mortality differs between registers due to various disease definitions. Dan Med J. 2014;61(5):A4840.

9. Christiansen C, Johansen M, Christensen S, O'Brien JM, Tønnesen E, Sørensen H. Preadmission metformin use and mortality among intensive care patients with diabetes: a cohort study. Crit Care. 2013; 17(5):R192.

10. Sørensen HT, Sabroe S, Olsen J. A framework for evaluation of secondary data sources for epidemiological research. Int J Epidemiol. 1996;25(2):435-442.

11. American Diabetes Association. Standards of medical care in diabetes 2014. Diabetes Care. 2014;37 Suppl 1:S14-S80.

12. Støvring H, Andersen M, Beck-Nielsen H, Green A, Vach W. Rising prevalence of diabetes: evidence from a Danish pharmaco-epidemiological database. Lancet. 2003;362(9383):537-538.

13. Thomsen RW, Friborg S, Nielsen JS, Schroll H, Johnsen SP. The Danish Centre for Strategic Research in Type 2 Diabetes (DD2): organization of diabetes care in Denmark and supplementary data sources for data collection among DD2 study participants. Clin Epidemiol. 2012;4(Suppl 1): $15-19$. 


\section{Publish your work in this journal}

Clinical Epidemiology is an international, peer-reviewed, open access, online journal focusing on disease and drug epidemiology, identification of risk factors and screening procedures to develop optimal preventative initiatives and programs. Specific topics include: diagnosis, prognosis, treatment, screening, prevention, risk factor modification,

Submit your manuscript here: http://www.dovepress.com/clinical-epidemiology-journal

\section{Dovepress}

systematic reviews, risk \& safety of medical interventions, epidemiology \& biostatistical methods, and evaluation of guidelines, translational medicine, health policies \& economic evaluations. The manuscript management system is completely online and includes a very quick and fair peer-review system, which is all easy to use. 